\title{
Behaviour and survival of pike, Esox lucius, with a retained lure in the lower jaw
}

\author{
R. ARLINGHAUS \\ Inland Fisheries Management Laboratory, Institute of Animal Sciences, Faculty of Agriculture and Horticulture, Humboldt- \\ University of Berlin, and Department of Biology and Ecology of Fishes, Leibniz-Institute of Freshwater Ecology and Inland \\ Fisheries, Berlin, Germany
}

\section{T. KLEFOTH}

Department of Biology and Ecology of Fishes, Leibniz-Institute of Freshwater Ecology and Inland Fisheries, Berlin, Germany

\author{
A. J. GINGERICH, M.R. DONALDSON, K. C. HANSON \& S. J. COOKE \\ Fish Ecology and Conservation Physiology Laboratory, Department of Biology, Carleton University, Ottawa, ON, Canada
}

\begin{abstract}
The behaviour and survival of pike, Esox lucius L., released with a retained lure in the mouth was studied relative to control fish, which simulated line breakage prior to landing. Behaviour was monitored during the first hour post-release with the aid of visual floats attached to the fish, and longer-term for 3 weeks, by means of externally attached radio transmitters. Lure-treated pike were less mobile during the first hour postrelease, but exhibited greater mobility and travelled further distances from the release area in the first $24 \mathrm{~h}$ after release than controls. From the second day after release, the behaviour of lure-treated pike was similar to control fish. No mortality occurred in a 3-week monitoring period. These results are indicative of only short-term behavioural impairments resulting from a retained lure and rapid resubmission of normal behaviour after simulated break-offs.
\end{abstract}

KEYWORDS: behavioural impairment, catch-and-release, fish welfare, lure, recreational fishing.

\section{Introduction}

Esocids such as muskellunge, Esox masquinongy Mitchell, and pike, Esox lucius L., are important targets for recreational anglers in the northern hemisphere (Pierce, Tomcko \& Schupp 1995; Fayram 2003; Arlinghaus \& Mehner 2004). However, the dentition and gill rakers of esocids are sharp, which can lead to so-called break-offs, i.e. fish breaking or cutting the main line or leader leaving bait/lure/ hook(s) in the mouth. Little is known about the mortality rates or sublethal reactions (e.g. behavioural alterations) of fish that break-off (Arlinghaus, Cooke, Lyman, Policansky, Schwab, Suski, Sutton \& Thorstad 2007a). A small number of studies examined the fate of hooks left in various species (e.g. Schill 1996;
Tsuboi, Morita \& Ikeda 2006) and the associated behavioural consequences (Thorstad, Næsje, Fiske \& Finstad 2003). However, no field study examined the behaviour and fate of predatory fish with retained artificial lures.

A fish that breaks the line and escapes with a retained lure might suffer immediate mortality because of lethal injury or predatory attacks by cannibalistic conspecifics, other fish species, fish-eating birds or mammals (Cooke \& Philipp 2004; Thorstad, Hay, Næsje, Chanda \& Økland 2004; Arlinghaus et al. 2007a), or delayed mortality, e.g. through impaired feeding (Tsuboi et al. 2006). If the individual fish survives, it may still suffer sub-lethal impairments such as reduced ability to flee (Cooke \& Philipp 2004; Schreer, Resch, Gately \& Cooke 2005; White, Schreer 
\& Cooke 2008). The various documented changes in behaviour caused by angling-related stressors (e.g. Gingerich, Cooke, Hanson, Donaldson, Hasler, Suski \& Arlinghaus 2007; Klefoth, Kobler \& Arlinghaus 2008; White et al. 2008) may be indicative of altered or impaired capability of a fish in sensing and responding to its environment. Thus, behavioural measures constitute sensitive indicators of the complex biochemical and physiological changes that occur in response to stress (Schreck, Olla \& Davis 1997) and are suitable to study the impact of a retained lure on fish. The influence of the lure can be quantified in field settings using positional telemetry and an experimental approach to observe behavioural reactions in fish that are released with (treatment) and without (control) a retained lure (Donaldson, Arlinghaus, Hanson \& Cooke 2008). In addition, telemetry allows not only the sub-lethal impacts of a retained lure in terms of behavioural change to be examined, but also the ultimate fate to be quantified if the fish is followed for a long time.

In the present study, adult pike were used as a model species to assess the impact of retained artificial lures on post-release behaviour and fate. Visual assessments of behaviour within the first hour after release were conducted to assess immediate behavioural reactions to a retained lure. This was coupled with longer term assessments of swimming activity and displacement for 3 weeks post-release. It was hypothesised that pike with a lure in the mouth would display behavioural alterations compared with fish released without a retained lure.

\section{Material and methods}

The study was conducted in May 2006 (with angling between 3 and 19 May 2006) on Lake Opinicon, a large (787 ha), shallow (mean depth $=4.5 \mathrm{~m}$ ), dimictic, mesotrophic, natural lake in eastern Ontario, Canada $\left(44^{\circ} 33^{\prime} 56.0^{\prime} \mathrm{N}, 76^{\circ} 19^{\prime} 23.6^{\prime} \mathrm{W}\right)$. The gear and angling methods used to capture pike were intended to reflect common tactics used by anglers (e.g. barbed hooks, Arlinghaus, Klefoth, Kobler \& Cooke 2008). Pike were captured from a boat by medium-action rods and multifilament $(16.3 \mathrm{~kg})$ test line. Fishing was conducted by actively casting or trolling a variety of artificial lures (see Arlinghaus et al. 2008 for details).

After hooking, fish were played for a fixed time of $60 \mathrm{~s}$ and then landed with a rubber net. After netting, the fish was placed into a cooler, filled with fresh lake water to minimise air exposure while unhooking. If the fish was deeply hooked, the barbed hook shank was cut with a wire cutter to minimise unhooking-related injuries (Arlinghaus et al. 2008) and all lures (and hooks) were removed after capture.

The study involved monitoring post-release behaviour at a common release site. This was done to expose all pike to the same release environment and to avoid site-specific post-release behaviours that could be associated with site fidelity of individual pike at the capture site. Pike were angled from randomly selected sites along the shoreline and over submerged macrophyte beds at distances of at least $250 \mathrm{~m}$ from the observation area. Fish from all treatment groups were returned to the common release site (fixed time in the cooler before release $10 \mathrm{~min}$ ) for post-release behavioural monitoring. Experimentation was limited to pike that appeared healthy (i.e. absence of fungal infections) and where injury associated with the angling gear was minimal (i.e. little or no bleeding). Also, only females were used (determined according to Casselman 1974) to avoid sex-specific variation in behaviour.

To determine the impact of leaving an artificial lure in the mouth on the subsequent behaviour, one lure treatment group $(n=12)$ and one lure control group $(n=10)$ was established to which individuals were randomly allocated. All fish were subjected to attachment of a float and an external radio transmitter to assess behaviour. To monitor behaviour at a fine scale within the first hour post-release, fish were fitted with a small, coloured Styrofoam float attached via a size eight J-type hook on a monofilament nylon line $(2.5 \mathrm{~m}$ long, $1.7 \mathrm{~kg}$ test line) into the superficial tissue posterior to the origin of the dorsal fin (Cooke \& Philipp 2004). Radio transmitters (Model PD-2 transmitters, Holohil Systems Inc., Carp, ON, Canada; weight in air $=3.7 \mathrm{~g}, 25 \times 13 \times 6 \mathrm{~mm}$, battery life 6 months, $120 \mathrm{~mm}$ antenna wire) were externally attached to the fish to monitor movement activity in the first 3 weeks post-release (described in detail in Cooke 2003). The entire process of attaching floats and transmitters lasted $<3 \mathrm{~min}$.

After attachment of float and transmitter, each fish in the control group was released at the common release point. The lure treatment group consisted of fish that, in addition to float and transmitter attachment, had a standardised 14-cm long soft plastic shad with one single and one treble hook placed in the lower jaw with no additional air exposure prior to release (i.e. fish were submerged in lake water throughout the lure placement that took $<10 \mathrm{~s}$ ). The single hook of the lure was punctured through the lower jaw and then the treble hook was placed in the middle of the lower jaw into the tongue using pliers. This procedure allowed the pike to feed as there remained enough space between the lure and the upper jaw. The control group 
was used to assess the impact of the lure attachment relative to the lure treatment group as both of these groups were treated the same way (i.e. externally tagged) but differed in the presence of a lure. Therefore, the relative difference in behaviour between the two groups indicated a lure effect.

The procedure of attaching external transmitters and floats without anaesthesia was necessary as the experimental design required a rapid approach to attach transmitter devices without the potential confounding effect of anaesthesia and internal surgeries (Cooke, Crossin, Patterson, English, Hinch, Young, Alexander, Healey, van der Kraak \& Farrell 2005). Although the technique developed here in consultation with animal care committees was deemed to cause discomfort to the pike, the strategies employed were intended to minimise physiological disturbance, for example by keeping fish in the water during all procedures. Moreover, pike are resilient to transmitter implantation, quickly returning to normal behavioural and metabolic patterns after release (Jepsen \& Aarestrup 1999).

All fish were released at the same release point (the littoral zone of a small bay, $44^{\circ} 33^{\prime} 56^{\prime} \mathrm{N}, 76^{\circ} 19^{\prime} 24^{\prime} \mathrm{W}$ ) located within a predefined observation area. The observation area surrounding the release point was 2.7 ha and was defined as the maximum detection range of radio-transmitters from the boat docks of the research station.

For the first hour following release, float movement was monitored from the boat docks and from boats to assess activity of each individual pike at a fine spatial scale. Stopwatches and maps were used to estimate the time until first movement post-release, rates of movement and distance travelled during the first hour. The duration within the first hour post-release that the fish was stationary (resting time as \% of first hour) was also determined. After $60 \mathrm{~min}$, the float and the hook were removed by approaching the float by boat and gently tugging on the float and leaving the fish unrestrained. Because the hook associated with the float was placed in minimally vascularised fin tissue, bleeding and injury was negligible (Cooke \& Philipp 2004).

Radio telemetry was used for 3 weeks post-release to assess the distances moved and to determine mortality for lure control and lure treatment fish. Radio tracking was performed manually from a boat using a handheld receiver (Lotek SRX_400 Telemetry Receiver, Lotek, ON, Canada) and a three element Yagi antenna. This method proved to be reliable for tracking pike that can be approached to about $2 \mathrm{~m}$ before eliciting a fleeing reaction (Kobler, Klefoth, Wolter, Fredrich \& Arlinghaus 2008). Pike were only tracked by boat if they were not detectable in the observation area from the shoreline. Each fish was tracked once per day for the first 3 days after release. Once a fish was located, its position was taken by a GPS unit (Garmin eTrex Summit, Olathe, Kansas, USA) with a precision of $\pm 5 \mathrm{~m}$. Minimally moved distances were standardised to $12 \mathrm{~h}$ and determined as the straight line between successive locations (e.g. release point to first location outside the observation area) and/or the nearest water distance between tracking points if a fish swam around a bay or an island. After the first 3 days and for 3 weeks in total, longer time intervals between successive locations were chosen and the distances moved were standardised to minimum moved distances per 3 days. Also, the distance to the release point in the days following release was assessed to analyse displacement patterns.

Continuous variables (e.g. distances moved, distances to release point) were contrasted between the treatment group and the control group using $t$-tests. Normality and homogeneity of variances for the dependent variables within factors were tested by Kolmogorov-Smirnov tests (normality) and Levene's tests (variance homogeneity). In case of deviations from the underlying assumptions of parametric tests $(P<0.05)$, continuous data were $\log _{\mathrm{e}}(X+1)$-transformed for statistical analysis, but data are presented untransformed. After transformation, all dependent variables met the assumptions for parametric tests $(P>0.05$ in all cases). Significance was assessed at $\alpha=0.05$ for all comparisons. All statistical tests were conducted using SPSS version 13.0.

\section{Results}

Total length of fish was not significantly different among treatments [controls $48.8 \pm 1.0 \mathrm{~cm}(n=10)$, lure treatment $50.6 \pm 2.9 \mathrm{~cm}(n=12), t=-0.538$, df $=20, P=0.596]$. Surface water temperature during the study period ranged from 14 to $17.2{ }^{\circ} \mathrm{C}$, and temperature at the capture and release day did not differ significantly among treatments, indicating equal spread of the sampling across the study period $(F=-0.931, \mathrm{df}=20, P=0.363)$. There were no significant differences in the distance from capture to the release point among treatment groups $(F=$ $-0.635, \quad \mathrm{df}=20, \quad P=0.533$, range $250-1756 \mathrm{~m}$ ). Also, in terms of handling time for transmitter attachment, there were no statistical differences between the lure treatment and the lure control groups $(251.3 \pm 39.2 \mathrm{~s}$ vs $169.5 \pm 22.8 \mathrm{~s}, t=-1.696, \mathrm{df}=$ $18, P=0.107)$.

All pike exhibited low swimming activity within the first hour post-release (Table 1), and no pike died 
Table 1. Short-term movement of two groups of pike within the first hour post-release (sample size in parentheses, average \pm SE)

\begin{tabular}{|c|c|c|c|}
\hline $\begin{array}{l}\text { Movement in time } \\
\text { interval post-release }\end{array}$ & Lure control & Lure treatment & Statistic \\
\hline $0-15 \min (\mathrm{m})$ & $18.8 \pm 9.6(10)$ & $4.2 \pm 2.9(12)$ & $t=2.125, \mathrm{df}=20, \boldsymbol{P}=\mathbf{0 . 0 4 9}$ \\
\hline $15-30 \min (\mathrm{m})$ & $6.4 \pm 2.6(10)$ & $1.1 \pm 0.5(11)$ & $t=2.095, \mathrm{df}=19, \boldsymbol{P}=\mathbf{0 . 0 5 0}$ \\
\hline $30-45 \min (\mathrm{m})$ & $11.3 \pm 4.1(8)$ & $24.8 \pm 21.1(11)$ & $t=-0.539, \mathrm{df}=17, P=0.597$ \\
\hline $45-60 \min (\mathrm{m})$ & $4.8 \pm 2.4(8)$ & $2.3 \pm 1.2(11)$ & $t=0.980, \mathrm{df}=17, P=0.341$ \\
\hline
\end{tabular}

Overall significant differences are indicated in bold.

immediately or as a result of attacks by conspecifics or other predators. Average distances moved were less than $50 \mathrm{~m}$ in the first hour in treatment and control groups (Fig. 1). Pike that were left with a lure in the mouth moved significantly less within the first hour post-release than control fish. They also spent significantly more time resting (i.e. no swimming activity at all) and took significantly longer time to initiate their first movement after release (measured in minutes) than controls (Fig. 1). The reduced movement of pike released with lures was most pronounced within the first 30 min post-release (Table 1).

None of the pike died within a post-release monitoring period of 3 weeks as indicated by substantial movement between successive locations. On average, each fish was followed for about 20 days post-release and there were no differences in tracking duration between treatment groups (controls: $20.8 \pm 2.3$ days; lure treatment: $19.0 \pm 2.3$ days; $t=0.575, \mathrm{df}=20$, $P=0.571)$. Movements were substantial and all pike left the release area within the first 2 days after release, predominantly in an easterly direction (Fig. 2).

Pike with a lure in the mouth moved significantly longer distances during the first day after release relative to controls (Table 2). With only one exception on day 2 after release, lure treatment pike consistently showed higher minimum swimming distances within the first 3 weeks post-release than lure controls, but these differences were not statistically significant.

While control fish were found in close proximity to the release site (on average within $105 \mathrm{~m}$ ) during the first $24 \mathrm{~h}$ after release, most lure treatment pike dispersed in an easterly direction (Fig. 2). Consequently, the distance from the release site was significantly larger for lure-treated fish relative to control fish on the first day after release (Table 2). There were no differences in distance to release point between treatments after day 1 post-release and the spatial distribution of both treatment groups was largely overlapping (Fig. 2; similar patterns were apparent in all tracking days after day 1 , but only the pattern after the first week after release is shown for illustrative purpose).

\section{Discussion}

It was expected that pike swimming away with an artificial lure retained in their mouth would exhibit behavioural alterations compared with control fish. The results supported this notion for the first hour and first day post-release. Pike with a retained lure moved significantly less than lure control fish in the first hour after release, but then showed increased movement and greater displaced distances in the first $24 \mathrm{~h}$ after release compared with lure controls. However, after the first day no statistical differences were found in the average displaced distance from the release site and in the average minimum movement rate between control and lure-treated pike. This indicated rapid resumption of normal behavioural patterns in agreement with previous studies in pike in a catch-and-release angling context (Klefoth et al. 2008). This statement must be interpreted with caution as the present study design did not record behaviour of pike pre-capture, and the movement and displacement variables were only tested relative to control fish. Control fish were externally tagged and captured by angling. It is therefore unknown how pike would behave normally in Lake Opinicon, i.e. unaffected by capture and tagging. However, this is a basic condition for all tagging studies where wild fish must be captured (Donaldson et al. 2008) and does not affect the main result of the present study because the short-term behavioural alteration observed in lure-treated pike was detected relative to appropriate control fish.

No pike released with a lure to simulate a break-off situation died in a 3-week post-release monitoring period. This provides evidence for limited lethal impacts of leaving lures in the mouth of pike over a short time period (i.e. up to 3 weeks). However, it is conceivable that delayed mortality might occur unnoticed in the period following the tracking study as a result of impaired feeding or infections at the hooking wounds. Further studies are needed to assess long-term impacts (i.e. at a temporal scale of months) on pike that break-off the fishing line and swim away with a retained lure. 

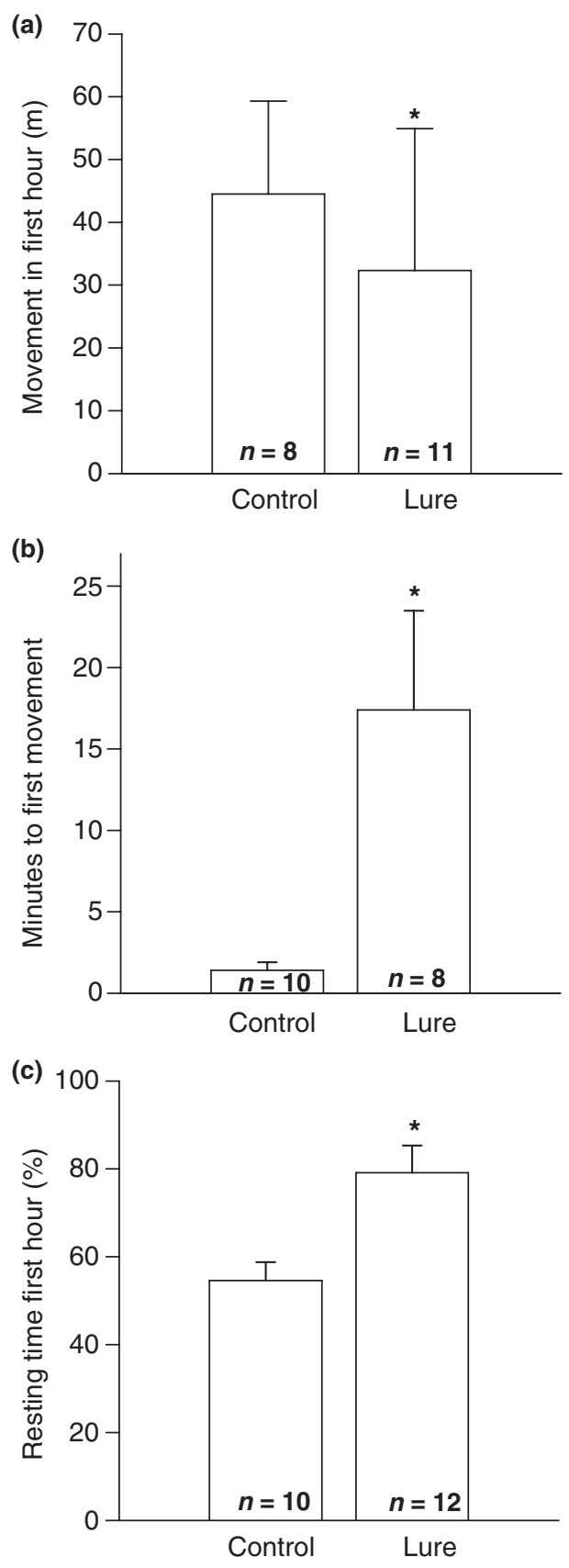

Figure 1. Behavioural patterns of two groups of pike in the first hour post-release in Lake Opinicon. *Significant differences among groups (average $\pm \mathrm{SE}$ ). Results of statistical tests were: (a) first hour movement rate tested on $\log _{\mathrm{e}}(X+1)$-transformed data: $t=2.157, \mathrm{df}=17, P=$ 0.046; (b) minutes to first movement: $t=-2.939$, $\mathrm{df}=16, P=0.034$; (c) percent resting of first hour: $t=-3.125$, df $=20, P=0.004$. Three fish in the lure treatment did not move at all within the first hour and were therefore excluded from the analysis of minutes to first movement.

In the first hour after release, lure-treated pike were less mobile than control fish, spent more time resting, and required more time between release and first movement. The cause of the reduced movement in the first hour post-release in lure-retained pike may be related to elevated stress and injury resulting from lure attachment. Moreover, appearance of a novel object in the mouth of pike may result in further increased levels of stress. Increased stress and fatigue as a result of angling-related stressors is known to reduce swimming ability of fish post-release (Schreer et al. 2005). This was reported in caught-and-released pike (Klefoth et al. 2008), in agreement with the results of the present study.

Within the first day after release, lure-treated pike exhibited a marked change in behaviour by moving longer distances and dispersing farther away from the release site compared with control fish. This swimming away probably started after full recovery from physiological disturbance. Recovery from angling-induced or similar stressors (e.g. handling) in pike varies between the indicator used, but full recovery is likely within the first $12 \mathrm{~h}$ (Soivio \& Oikari 1976; Schwalme \& Mackay 1985a,b; Armstrong, Lucas, Priede \& de Vera 1989). Although it was not possible to identify precisely when hyperactivity of lure-treated fish started, it is likely that recovery of physiological homeostasis preceded the swimming activity bursts.

In line with arguments put forward by Rose (2007), the increased swimming activity of pike in response to lure attachment in the first day postrelease is interpreted as escape behaviour, to seek refuge or get rid of the disturbing stimulus through swimming and similar avoidance and flight reactions. Beukema (1970) showed that pike were able to remember capture by an artificial lure leading to reduced catchability post-release, which is indicative of the disturbing and probably threatening stimulus associated with artificial lures. A lure partly hanging out of the mouth will also continuously create drag when the fish moves through the water, even if movement is only localised and fine-scale. A natural reaction to this disturbance stimulus might be to flee and seek refuge (Rose 2007).

Lure-treated pike resumed normal behaviour after day 1 as indicated by a lack of significant differences in moved distances and displacement patterns between lure treatment pike and control fish. This might have been facilitated by pike losing the lure over time or becoming accustomed to the disturbing stimulus. Unfortunately, it was not possible to determine whether pike were indeed able to expel the lures. Although the research team attempted to recapture pike by angling, none were caught. Moreover, for logistical reasons, the research team was not able to employ other fishing techniques (e.g. electric fishing) to recapture pike. It is, 


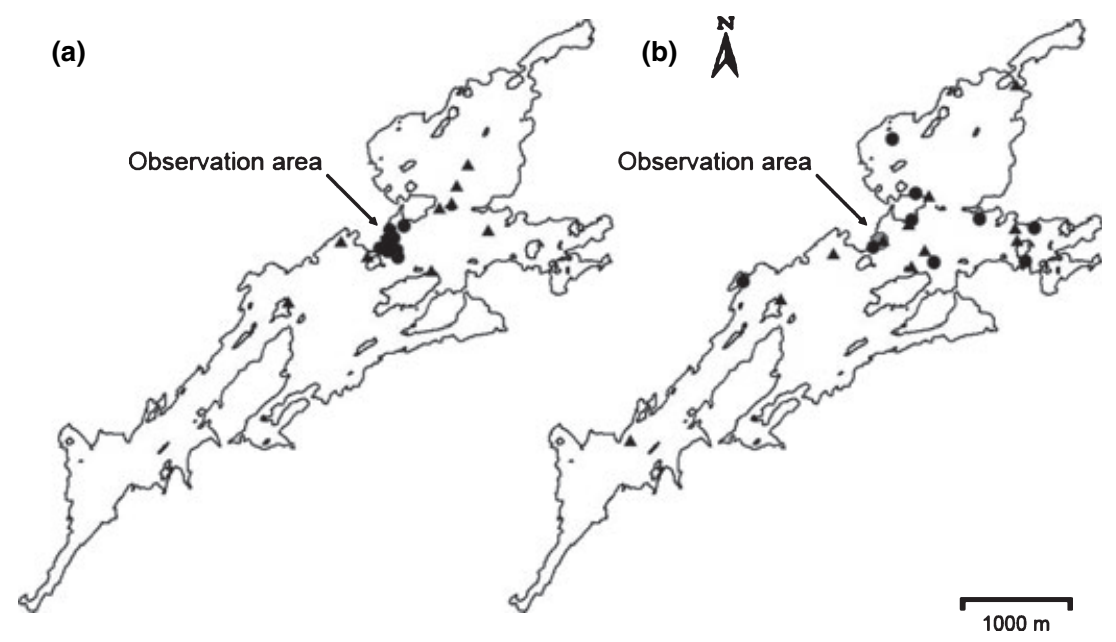

Figure 2. Displacement patterns of lure control (circles) and lure treatment pike (triangles) after 1 day (a, left) and 1 week (b, right) post-release in Lake Opinicon. All fish were released at a common release point in a common observation area ( $2.7 \mathrm{ha})$, which is indicated by the arrows and the grey area (visible in panel B).

Table 2. Long-term movement and displacement of two groups of pike (sample size in parentheses, average \pm SE)

\begin{tabular}{|c|c|c|c|}
\hline Movement variable & Lure control & Lure treatment & Statistic \\
\hline \multicolumn{4}{|c|}{ Minimal movement rate post-release } \\
\hline Day $1\left(\mathrm{~m} 12 \mathrm{~h}^{-1}\right)$ & $58.8 \pm 19.5(10)$ & $314.5 \pm 66.1(12)$ & $t=-3.710, \mathrm{df}=12.9, \boldsymbol{P}=\mathbf{0 . 0 0 3}$ \\
\hline Day $2\left(\mathrm{~m} 12 \mathrm{~h}^{-1}\right)$ & $260.9 \pm 86.6(10)$ & $189.6 \pm 57.5(10)$ & $t=0.686, \mathrm{df}=18, P=0.502$ \\
\hline Day $3\left(\mathrm{~m} 12 \mathrm{~h}^{-1}\right)$ & $155.9 \pm 71.3(10)$ & $204.7 \pm 55.2(11)$ & $t=-0.547, \mathrm{df}=19, P=0.591$ \\
\hline 1st week (m 3 days $^{-1}$ ) & $232.4 \pm 63.2(9)$ & $478.8 \pm 148.2(11)$ & $t=-1.529, \mathrm{df}=13.4, P=0.150$ \\
\hline 2 nd week (m 3 days $^{-1}$ ) & $70.5 \pm 32.4(9)$ & $260.7 \pm 81.6(10)$ & $t=-2.167, \mathrm{df}=11.7, P=0.052$ \\
\hline 3 rd week (m 3 days $^{-1}$ ) & $195.7 \pm 64.2(7)$ & $431.1 \pm 190.1(7)$ & $t=-1.173, \mathrm{df}=12, P=0.263$ \\
\hline \multicolumn{4}{|c|}{ Distances from release point post-release } \\
\hline Day 1 (m) & $104.9 \pm 32.1(10)$ & $664.5 \pm 131.1(12)$ & $t=-4.147, \mathrm{df}=12.3, \boldsymbol{P}=\mathbf{0 . 0 0 1}$ \\
\hline Day 2 (m) & $535.2 \pm 176.6(10)$ & $649.3 \pm 121.4(10)$ & $t=-0.532, \mathrm{df}=18, P=0.601$ \\
\hline Day $3(\mathrm{~m})$ & $785.2 \pm 189.5(10)$ & $607.9 \pm 110.3(11)$ & $t=0.809, \mathrm{df}=14.6, P=0.432$ \\
\hline Day 7 (m) & $1089.2 \pm 197.8(8)$ & $1189.0 \pm 308.3(11)$ & $t=-0.258, \mathrm{df}=18, P=0.799$ \\
\hline Day $14(\mathrm{~m})$ & $1133.6 \pm 198.0(9)$ & $1426.7 \pm 306.4(11)$ & $t=-0.684, \mathrm{df}=17, P=0.503$ \\
\hline Day $21(\mathrm{~m})$ & $899.1 \pm 198.0(7)$ & $1127.7 \pm 288.4(7)$ & $t=-0.653, \mathrm{df}=12, P=0.526$ \\
\hline
\end{tabular}

Note different units for first 3 days compared to thereafter resulting from inconsistent tracking intervals (with more effort devoted to the first 3 days). Significant differences are indicated in bold.

however, unlikely that the pike in this study were all able to get rid of the lure quickly as the treble hook was tightly anchored in the tongue. More research is required to reveal for how long lures remain in the mouth before being lost by the fish following break-off. However, from a fish welfare perspective (Arlinghaus, Cooke, Schwab \& Cowx 2007b), the short-term behavioural changes observed in the present study provide sufficient evidence to advocate that anglers should minimise the risk of losing hooked pike (and other toothy predators) to minimise negative impacts on the well-being of fish even if the behavioural impacts are not lethal. This can be done by using appropriate gear (e.g. metal-leaders).

\section{Acknowledgments}

Funding was provided by the German Academic Exchange Service (DAAD) to TK, the AdaptfishProject funded through the Pact for Innovation and Research by the Leibniz-Community to RA (http:// www.adaptfish.igb-berlin.de) and the Canadian Foundation for Innovation and the Ontario Research Fund. The study was conducted in accordance with the Canadian Council on Animal Care as approved by the Carleton University Care Committee. We thank the staff at the Queen's Biology Station for support and technical assistance, particularly Frank Phelan and Floyd Connor, students of the Cooke lab for help with 
field work and Cory Suski for comments on a previous draft. We thank several anonymous reviewers for challenging reviews and Niels Jepsen and Ian Cowx for support.

\section{References}

Arlinghaus R. \& Mehner T. (2004) A management-orientated comparative analysis of urban and rural anglers living in a metropolis (Berlin, Germany). Environmental Management 33, 331-344.

Arlinghaus R., Cooke S.J., Lyman J., Policansky D., Schwab A., Suski C., Sutton S.G. \& Thorstad E.B. (2007a) Understanding the complexity of catch-and-release in recreational fishing: an integrative synthesis of global knowledge from historical, ethical, social, and biological perspectives. Reviews in Fisheries Science 15, 75-167.

Arlinghaus R., Cooke S.J., Schwab A. \& Cowx I.G. (2007b) Fish welfare: a challenge to the feelings-based approach, with implications for recreational fishing. Fish and Fisheries 8, 57-71.

Arlinghaus R., Klefoth T., Kobler A. \& Cooke S.J. (2008) Sizeselectivity, injury, handling time and determinants of initial hooking mortality in recreational angling for northern pike (Esox lucius): the influence of type and size of bait. North American Journal of Fisheries Management 28, 123-134.

Armstrong J.D., Lucas M.C., Priede I.G. \& de Vera L. (1989) An acoustic telemetry system for monitoring the heart rate of pike, Esox lucius L., and other fish in their natural environment. Journal of Experimental Biology 143, 549-552.

Beukema J.J. (1970) Acquired hook-avoidance in the pike Esox lucius L. fished with artificial and natural baits. Journal of Fish Biology 2, 155-160.

Casselman J.M. (1974) External sex determination of northern pike, Esox lucius Linnaeus. Transactions of the American Fisheries Society 103, 343-347.

Cooke S.J. (2003) Externally attached radio transmitters do not affect the parental care behaviour of rock bass. Journal of Fish Biology 62, 965-970.

Cooke S.J. \& Philipp D.P. (2004) Behavior and mortality of caught-and-released bonefish (Albula spp.) in Bahamian waters with implications for a sustainable recreational fishery. Biological Conservation 118, 599-607.

Cooke S.J., Crossin G.T., Patterson D.A., English K.K., Hinch S.G., Young J.L., Alexander R.F., Healey M.C., van der Kraak G. \& Farrell A.P. (2005) Coupling non-invasive physiological assessments with telemetry to understand inter-individual variation in behaviour and survivorship of sockeye salmon: development and validation of a technique. Journal of Fish Biology 67, 1342-1358.

Donaldson M.R., Arlinghaus R., Hanson K.C. \& Cooke S.J. (2008) Enhancing catch-and-release science with biotelemetry. Fish and Fisheries 9, 79-105.
Fayram A.H. (2003) A comparison of regulatory and voluntary release of muskellunge and walleyes in northern Wisconsin. North American Journal of Fisheries Management 23, 619-624.

Gingerich A., Cooke S.J., Hanson K., Donaldson M., Hasler C., Suski C. \& Arlinghaus R. (2007) Evaluation of the interactive effects of air exposure and water temperature on the condition and survival of angled and released fish. Fisheries Research 86, 169-178.

Jepsen N. \& Aarestrup K. (1999) A comparison of the growth of radio-tagged and dye-marked pike. Journal of Fish Biology 55, 880-883.

Klefoth T., Kobler A. \& Arlinghaus R. (2008) The impact of catch-and-release angling on short term behaviour and habitat choice of northern pike (Esox lucius L.). Hydrobiologia 601, 99-110.

Kobler A., Klefoth T., Wolter C., Fredrich F. \& Arlinghaus R. (2008) Contrasting pike (Esox lucius L.) movement and habitat choice between summer and winter in a small lake. Hydrobiologia 601, 17-27.

Pierce R.B., Tomcko C.M. \& Schupp D.H. (1995) Exploitation of northern pike in seven small North-Central Minnesota lakes. North American Journal of Fisheries Management 15, 601-609.

Rose J.D. (2007) Anthropomorphism and 'mental welfare' of fishes. Diseases of Aquatic Organisms 75, $139-154$

Schill D.J. (1996) Hooking mortality of bait-caught rainbow trout in an Idaho trout stream and a hatchery: implications for special-regulation management. North American Journal of Fisheries Management 16, 348-356.

Schreck C.B., Olla B.L. \& Davis M.W. (1997) Behavioural responses to stress. In: G.K. Iwama, A.D. Pickering, J.P. Sumpter \& C.B. Schreck (eds) Fish Stress and Health in Aquaculture. Cambridge: Cambridge University Press, pp. 145-170.

Schreer J.F., Resch D.M., Gately M.L. \& Cooke S.J. (2005) Swimming performance of brook trout after simulated catch-and-release angling: looking for air exposure thresholds. North American Journal of Fisheries Management 24, 1513-1517.

Schwalme K. \& Mackay W.C. (1985a) The influence of angling-induced exercise on the carbohydrate metabolism of northern pike (Esox lucius L.). Journal of Comparative Physiology B 156, 67-75.

Schwalme K. \& Mackay W.C. (1985b) The influence of exercise-handling stress on blood lactate, acid-base, and plasma glucose status of northern pike (Esox lucius L.). Canadian Journal of Zoology 63, 1125-1129.

Soivio A. \& Oikari A. (1976) Haematological effects of stress on a teleost, Esox lucius L. Journal of Fish Biology 8, 397411. 
Thorstad E.B., Næsje T.F., Fiske P. \& Finstad B. (2003) Effects of hook and release on Atlantic salmon in the River Alta, northern Norway. Fisheries Research 60, 293-307.

Thorstad E.B., Hay C.J., Næsje T.F., Chanda B. \& Økland F. (2004) Effects of catch-and-release angling on large cichlids in the subtropical Zambezi River. Fisheries Research 69, 141-144.
Tsuboi J., Morita K. \& Ikeda H. (2006) Fate of deep-hooked white-spotted charr after cutting the line in a catch-andrelease fishery. Fisheries Research 79, 226-230.

White A.J., Schreer J.S. \& Cooke S.J. (2008) Behavioral and physiological responses of the congeneric largemouth (Micropterus salmoides) and smallmouth bass (M. dolomieu) to various exercise and air exposure durations. Fisheries Research 89, 9-16. 